\title{
Documentação Pedagógica: observar, registrar e (re)criar significados
}

\begin{abstract}
Resumo
A documentação pedagógica não se confunde com mero registro de práticas e, nem tampouco, representa 'adereço' que se encaixe em qualquer gramática pedagógica e em qualquer perspectiva curricular de educação infantil. Essas são as defesas essenciais trazidas no presente artigo que recorre a um acumulado de reflexões que vêm sendo construídas dentro deste campo e que elucidam aspectos conceituais que fundamentam a documentação pedagógica como um empreendimento investigativo, assentadas nos preceitos da educação democrática e implicadas com a qualidade das experiências de aprendizagem das crianças e dos demais atores educacionais. Compreendemos também que a estratégia da documentação pedagógica se alinha à família das pedagogias participativas e contribui em tornar visível uma determinada imagem de criança, de professor e de escola.
\end{abstract}

Palavras-chave: Documentação Pedagógica. Observação. Registro. Pedagogias Participativas. Educação Infantil.

\section{Mônica Appezzato Pinazza}

Universidade de São Paulo - USP

- São Paulo/SP - Brasil mapin@usp.br

\section{Paulo Sérgio Fochi}

Universidade de São Paulo - USP

- São Paulo/SP - Brasil

paulo.fochi@hotmail.com

\section{Para citar este artigo:}

PINAZZA, Mônica Appezzato; FOCHI, Paulo Sérgio. Documentação Pedagógica: observar, registrar e (re)criar significados. Revista Linhas. Florianópolis, v. 19, n. 40, p. 184-199, maio/ago. 2018. 


\title{
Pedagogical Documentation: to observe, to record and (re)create meanings
}

\begin{abstract}
The pedagogical documentation should not be misunderstood as a practice of recording and neither an "ornament" that fits into any pedagogical grammar and any curricular perspective of early childhood education. These arguments presented in this article uses an accumulation of reflections that have been constructed within this field and that elucidate conceptual aspects that base pedagogical documentation as a research enterprise, based on the precepts of democratic education and implied with the quality of children learning experiences and other educational actors. We also understand that the strategy of pedagogical documentation aligns the family of participatory pedagogies and contributes to making visible a certain image of children, teachers and schools.
\end{abstract}

Keywords: Pedagogical Documentation. Observation. Documentation. Participatory Pedagogies. Early Childhood Education. 
Na educação infantil, os documentos produzidos por especialistas em meados dos anos de 1990, num anúncio do que viria a ser consagrado pelos textos legais mandatórios a partir da LDB n. 9394/96 e, mais tarde, nas Diretrizes Curriculares Nacionais para a Educação Infantil - DCNEI (1999, revisada em 2009), parecem firmar o compromisso em não situar a primeira etapa da educação básica em uma pedagogia qualquer.

As concepções de criança, de currículo e de educação infantil, alinhadas aos princípios éticos, estéticos e políticos que encontramos nas DCNEI declaram uma visão de mundo democrática, aberta e sensível à pluralidade, que acolhe o universo das crianças na construção das suas jornadas de aprendizagem, reposicionando o papel do adulto na relação educativa.

Essas ideias percebidas nas orientações legais que dispomos atualmente são muito próximas das concepções que encontramos nas diferentes propostas curriculares das pedagogias participativas. Assumimos, aqui, a premissa de que as pedagogias participativas produzem, segundo Oliveira-Formosinho (2007, p. 15) “uma ruptura com uma pedagogia tradicional transmissiva para promover outra visão de ensinoaprendizagem e dos ofícios de aluno e professor”. A centralidade da família das pedagogias participativas está na participação dos atores na construção do conhecimento, refutando assim a ideia presente nas pedagogias transmissivas de conhecimento a ser "transferido".

Ocorre que, na medida em que se busca a construção de um novo paradigma na pedagogia realizada nas escolas de educação infantil, também começa a se fazer necessária a construção de uma nova didática de trabalho, já que os modelos que conhecemos não respondem à complexidade, tanto da atuação das crianças como do profissional que com elas trabalha.

$\mathrm{Na}$ família das pedagogias participativas, encontramos diferentes propostas curriculares em curso, que concretizam as concepções anteriormente anunciadas e assumem a práxis como lócus da Pedagogia (OLIVEIRA-FORMOSINHO, 2011; PINAZZA, 2014; FOCHI, 2016). A título de exemplo, poderíamos citar o High Scope, o Movimento da Escola Moderna - MEM, a Pedagogia-em-Participação, e com destaque, às abordagens italianas, inspiradas fortemente nos trabalhos de Loris Malaguzzi. 
Localizamos em cada uma dessas abordagens alguns pontos de convergência na reconceitualização da organização do espaço, da gestão do tempo, da oferta de materiais, dos diferentes arranjos nos agrupamentos de crianças e em especial, do papel do adulto. Evidentemente, sendo a pedagogia uma ciência que se constrói na ação situada (OLIVEIRA-FORMOSINHO, 2007; PINAZZA, 2014), os pontos anteriormente elencados concretizam concepções e oferecem pistas na reelaboração desta nova didática.

Especialmente na experiência preconizada por Loris Malaguzzi no Norte da Itália, em Reggio Emilia, um outro elemento soma-se na redefinição do trabalho educativo nas creches e pré-escolas, a documentação pedagógica.

O tema da documentação pedagógica nos serviços educativos voltados à primeira infância na Itália tem sido exaustivamente refletido tanto no âmbito da pesquisa acadêmica quanto no âmbito das práticas educativas. A prática da documentação pedagógica é reconhecida como condição indispensável para garantir a construção de uma memória educativa, de evidenciar o modo como as crianças constroem conhecimento, de fortalecer uma identidade própria da educação das crianças pequenas e da construção da qualidade dos contextos educativos (FOCHI, 2016).

Neste artigo, procuramos refletir a respeito dessa prática, tentando estabelecer alguns paralelos com as diferentes interpretações que encontramos no cenário brasileiro, com o intuito de problematizar e, especialmente, mostrar sua produtividade para o fortalecimento de uma dada pedagogia.

\section{A documentação pedagógica no cenário brasileiro}

Com a difusão da experiência de Reggio Emilia pelo mundo todo, o tema da documentação pedagógica ganhou destaque e tem ocupado um espaço importante entre os temas de formação de professores e da pesquisa educacional.

Em recente pesquisa realizada no Brasil, "Documento técnico contendo estudo sobre as experiências exitosas que já utilizam a documentação pedagógica na educação infantil nos segmentos creche e pré-escola" (BRASIL, 2017), notou-se uma forte presença dessa temática no interior das instituições de educação infantil públicas e privadas 
(especialmente nas regiões sul e sudeste), além de ser possível afirmar que nos últimos anos tem havido um interesse também dentro do universo acadêmico.

De acordo com a referida pesquisa, foram encontradas oito dissertações e sete teses (BDBTD¹), e dez artigos em periódicos científicos (Scielo e Repositório de Periódico da Capes) de autores brasileiros com as palavras chave "documentação-pedagógica”. Estas produções datam a partir do ano de 2009 e concentram-se especialmente nos últimos quatro anos. Há aqui um dado coincidente, pois da mesma forma que boa parte das escolas que dizem trabalhar com a documentação pedagógica se concentram nas regiões sul e sudeste, as pesquisas encontradas também são basicamente oriundas dessas duas regiões.

Além disso, em termos de publicações em livros, foram identificadas 24 obras com foco na documentação pedagógica e dentre essas, 20 traduções e quatro obras originalmente produzidas no Brasil. As traduções encontradas são, em sua totalidade, fruto direto ou indireto da experiência de Reggio Emilia, na Itália².

Com uma produção ainda discreta, a temática da documentação pedagógica ganha relevo no campo educacional brasileiro ao tempo da intensificação dos debates que trazem novamente em cena perspectivas pedagógicas participativas, alicerçando propostas curriculares para todos os níveis educacionais.

As documentações pedagógicas produzidas por professores e crianças das instituições de educação infantil italianas, tornaram-se pauta obrigatória nos discursos de formadores e, apressadamente, foram tomados como "modelos" por profissionais com atuação direta com as crianças.

Dizer que se faz "documentação pedagógica” passou a significar, no campo da educação, alusão a uma prática pedagógica de vanguarda, distanciada das formas de atuação das criticadas pedagogias transmissivas, desrespeitosas das potencialidades infantis e centralizadas nos conteúdos e nas intervenções dos adultos. Ou seja, aquilo que

\footnotetext{
${ }^{1}$ Banco digital brasileiro de teses e dissertações.

${ }^{2}$ As traduções que não são referentes à experiência educativa de Reggio Emilia, assumem que o trabalho com a documentação pedagógica em sua localidade é inspirado no trabalho das escolas de Reggio Emilia. A título de exemplo, o próprio livro "As cem linguagens" reúne não apenas relatos e textos dos educadores italianos, mas também de como essa experiência tem impactado o cenário norte-americano.
} 
se chama de "documentação pedagógica" apresenta-se como uma espécie de condutora natural de profundas transformações nas práticas da educação infantil.

Não tardou para que isso se revelasse um grande equívoco, mesmo porque o que se pratica correntemente sob a denominação de "documentação pedagógica”, não raro, se trata de uma coleção de meros registros escritos, fotográficos, em vídeos ou em áudios, que não atingem o estatuto de uma documentação pedagógica e tampouco provocam a tão sonhada transformação na prática educativa.

Quando o tema “documentação pedagógica” constitui pauta dos encontros de formação de profissionais da educação infantil ${ }^{3}$ - professores e/ou gestores (diretores e coordenadores pedagógicos) -, as manifestações iniciais são reveladoras de que se designa indistintamente "registro" e “documentação pedagógica”. Esse dado é reafirmado pela pesquisa recente sobre o tema (BRASIL, 2017) que recolhe mais de 100 exemplares de escolas e cruza com as concepções apontadas por elas a respeito do tema, evidenciando que há uma forte confusão entre o que se denomina e o que se pratica como “documentação pedagógica”. Percebe-se que, muitas vezes, há verdadeiramente um esforço de investir em formas de registrar as práticas e as realizações das crianças e de transformar os registros em algo capaz de orientar o planejamento e o monitoramento de todo processo educativo.

Em levantamentos prévios realizados em processos formativos, os profissionais mencionam uma série de registros frequentes nas unidades de educação infantil. Indicam a presença de uma profusão de registros intitulados indiscriminadamente: agendas; 'diários de bordo'; cadernos itinerantes/memórias com impressões e relatos das famílias; painéis informativos da criança e da família; portfólio da criança; portfólio do agrupamento.

Contudo, a questão apontada, além da má qualidade dos registros, é exatamente a desvinculação com o planejamento educativo. Na maioria dos casos relatados pelas participantes das diferentes formações, percebemos que o registro é utilizado como "prestador de contas" para as famílias ou mesmo para a própria instituição. Algumas

\footnotetext{
3 Referimo-nos, aqui, às diversas experiências que ambos os autores do artigo têm vivenciado em formações de redes municipais e de escolas privadas, com professores e gestores de educação infantil, sobre o tema da documentação pedagógica.
} 
vezes, em formato de avaliação. Ao mesmo tempo, há uma evidente dificuldade em demonstrar como tais registros são úteis para o professor construir o seu percurso educativo junto das crianças.

As queixas recorrentes giram em torno das enormes dificuldades que se tem em registrar os acontecimentos no cotidiano das instituições de educação infantil e de sistematicamente utilizá-los como indícios para orientar o planejamento educativo. Nos argumentos, aparecem as limitações temporais e mesmo a falta de clareza do que é digno de ser observado e de ser registrado.

A respeito desse tópico é importante recuperar o que Moss (2010), Paige-Smith e Craft (2010) argumentam sobre as condições que institucionalmente são criadas para garantir, ao professor, a reflexão sobre o seu próprio fazer. Ou seja, não se trata apenas de compreender que os registros cotidianos dos professores precisam orientar o seu próprio fazer, mas de construir institucionalmente a possibilidade de que a reflexão a partir dos registros aconteça como parte do seu trabalho. É também uma questão de tempo e espaço.

Os mesmos autores vão alertar que, ao criarmos essa demanda para o professor, contribuímos com a sua valorização e reinvenção do seu papel, superando a visão de um "técnico" rumo a um profissional que saiba acolher a subjetividade e o diálogo necessários na educação infantil.

Outro problema, por vezes encontrado em relação aos registros, é a sua limitada potência informativa, seja para monitoramento de práticas, seja para o planejamento de ações futuras. Constata-se, com frequência, um desperdício de tempo e energia na realização de registros plurais, que se perdem totalmente ou são subutilizados, como fontes de informação sobre o que os professores e as crianças experienciam e produzem no cotidiano da educação infantil. Em encontros de formação, os próprios profissionais dão seus testemunhos, indicando a inocuidade de muitos dos registros que fazem e colecionam.

São muito comuns depoimentos como: "de que valem tantos registros? O importante é dar mais atenção para as crianças"; "não temos mais onde guardar tantos materiais, que nem se sabe para que valem"; "perde-se um tempo que não se tem, para 
fazer registros, registros, registros e para quê?" "com essa moda de fazer documentação, as professoras só falam em "portfólios, portfólios"; "eu vou fazendo registros, registros, registros, que eu até me perco. Daí é difícil para fazer o relatório das crianças e os portfólios para mostrar para os pais". Essas falas colecionadas nos cursos de formação denotam grande incompreensão dos fundamentos da documentação pedagógica e mais ainda, reafirmam que o tema da documentação pedagógica no Brasil ainda é visto como um mero acessório.

Mas, então, o que significa “documentação pedagógica”?

O primeiro ponto de elucidação é, portanto, o fato de que nem todo registro produzido gera documentação pedagógica, mas que toda documentação pedagógica depende de registros de boa qualidade. É importante compreender essa diferenciação, pois, se por um lado não podemos resumir a documentação pedagógica aos registros, por outro, precisamos compreender que a ideia sistemática dos registros é um dos pilares centrais para poder ver, interpretar e projetar (MALAGUZZI, 2001, 1995; HOYUELOS, 2006; RINALDI, 2012; FOCHI, 2015).

São os professores e gestores que dão pistas de que há uma tendência de se fazer documentação pedagógica, desconsiderando o que há de mais elementar e constitutivo dessa prática: uma densa discussão sobre a gramática pedagógica orientadora do currículo e definidora de propósitos educativos a serem partilhados em uma instituição de educação infantil.

Dahlberg, Moss e Pence (2003), ao apresentarem a documentação pedagógica como "um instrumento vital para a criação de uma prática pedagógica reflexiva e democrática”, destacam seu papel "no discurso da construção de significado" (p. 191). Com isso, esses autores identificam o caráter de prática investigativa da documentação pedagógica, que vai além do registro de observações, posto que implica a interposição daquele que documenta na construção de novos significados. Advertem:

O significado não provém apenas do ver ou observar, ao contrário ele é construído. [...] A prática da documentação não pode, de modo algum, existir à parte do nosso envolvimento no processo [...] (DAHLBERG, MOSS E PENCE, 2003, p. 193) 
Complementam essa argumentação, acentuando a natureza seletiva e contextual da documentação pedagógica. Como dizem: “o que documentamos representa uma escolha, uma escolha entre muitas outras escolhas" (p. 193). Os autores nos ajudam a perceber nossa responsabilidade frente ao ato educativo, tirando a isenção que muitas vezes aparece nos discursos educativos.

Disso conclui-se que a documentação pedagógica se assenta em uma eleição do que merece ser documentado, da interpretação possível do que se toma como objeto de observação e de registro em um dado contexto.

Essa construção interpretativa traz subjacente uma dada gramática pedagógica, orientadora de uma determinada forma de pensar, organizar e conduzir a ação educativa, que, em última instância, define as perguntas formuladas às quais uma boa observação e uma produção de registros do observado devem tentar responder.

Alinhadas a essa perspectiva, estão as formulações de Gandini, Edwards e colabores (2002), que advertem que a documentação pedagógica não pode ser considera "uma mera coleta de dados de maneira distante, objetiva e descompromissada" (p. 151). Para as autoras, a documentação deve ser vista "como uma observação aguçada e uma escuta atenta, registrada através de uma variedade de formas pelos educadores que estão contribuindo conscientemente com sua perspectiva pessoal” (p. 151).

Gandini e Edwards (2002) propõem a documentação como um ciclo de investigação, composto de diferentes etapas desde a formulação de perguntas, passando pela observação, registro e produção de dados, pela organização dos dados observados e registrados, até chegar na análise e interpretação dos registros produzidos, o que permitirá a reformulação de perguntas e a composição de projetos e planejamentos futuros.

De acordo com as autoras, esse ciclo repete-se numa espiral ascendente, fruto de aprendizagens sucessivas de todos os atores (adultos e crianças) implicados na prática educativa e de (re)criação de significados àquilo que se pensa e faz no cotidiano de um contexto de educação infantil.

Na Figura 1, a representação gráfica do ciclo da documentação pedagógica. 


\section{O PROCESSO DE DOCUMENTAÇĀO COMO UM CICLO DE INVESTIGAÇĀO}

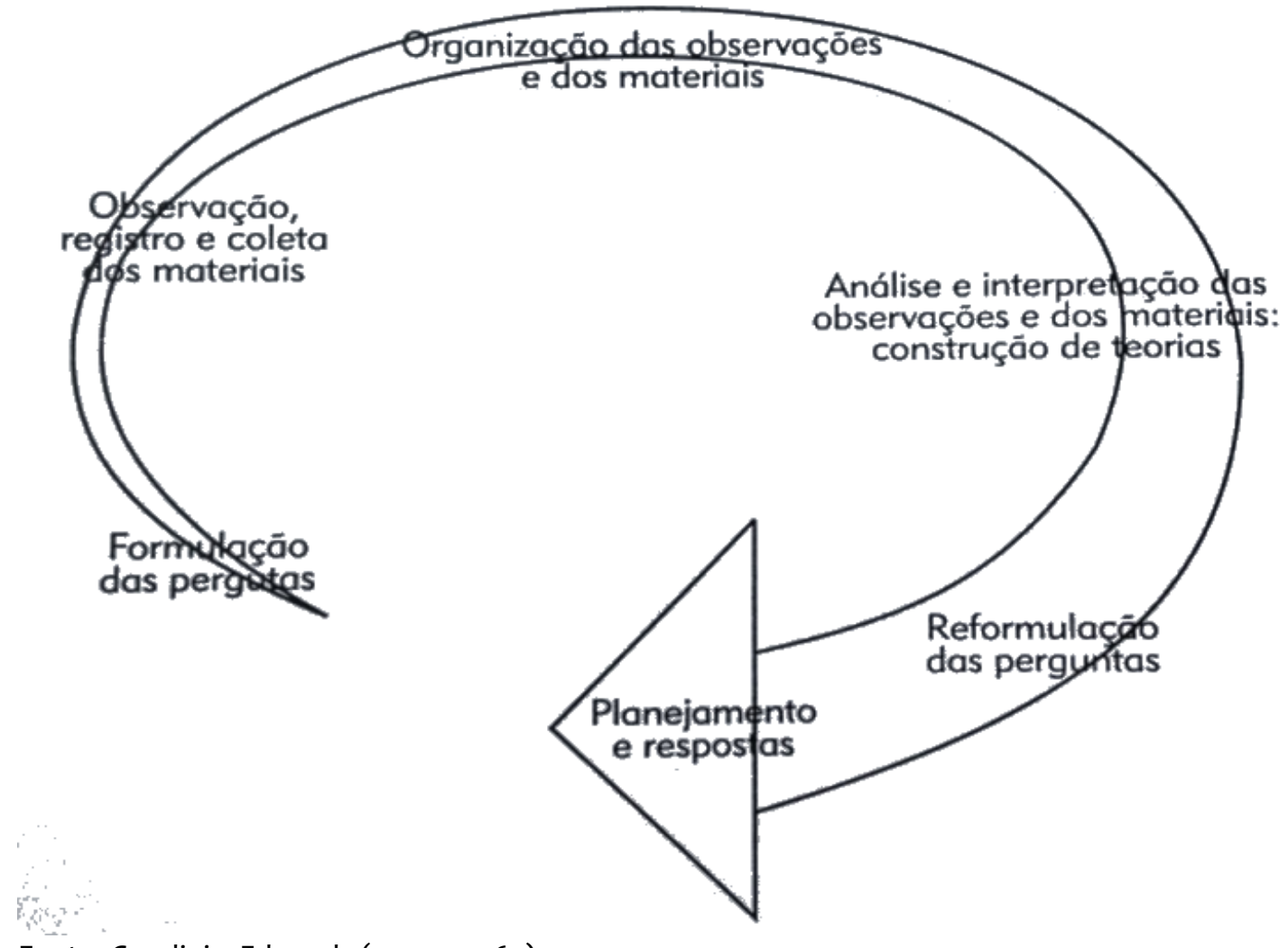

Fonte: Gandini e Edwards (2002, p. 162).

Gandini e Edwards (2002) atribuem à documentação pedagógica um papel essencial na qualidade das práticas educativas porque permite aos professores planejarem circunstâncias propícias às experiências de aprendizagem para as crianças, ao mesmo tempo em que favorece o desenvolvimento profissional e os processos comunicativos entre os adultos em um contexto de trabalho.

Se por um lado é importante compreender a relação e diferenciação entre registro e documentação pedagógica, por outro, entendemos que é importante desnaturalizar o conceito de observação. 


\title{
A observação: técnica essencial da documentação pedagógica
}

Como eu faço para observar todas as crianças, individualmente, num dia, sem deixar de fazer o meu trabalho com o grupo todo? Como eu defino o que devo observar? O que é mais importante eu observar? Como que eu faço pra registrar, se eu tenho que dar conta de toda a turma?

Essas são algumas das questões relativas às práticas de observação mais recorrentes quando se tematiza a documentação pedagógica nos cursos de formação.

Se a documentação pedagógica pode ser definida como uma prática investigativa, nada mais coerente do que buscar no campo da metodologia de pesquisa inspirações para compreender a observação como uma técnica de investigação de que podem se valer pesquisadores e, também, professores(as) da educação infantil, como investigadores de suas próprias práticas.

Uma importante contribuição vem do campo da psicologia que recorre essencialmente à observação para a composição interpretativa dos fenômenos estudados. Woodworth e Marquis (1971) destacam o caráter seletivo da observação e asseveram que o bom observador tem clareza do objeto de sua atenção e interesse. Nas palavras dos autores:

\begin{abstract}
A primeira coisa a notar-se em relação a importante questão de como poderá o indivíduo tornar-se melhor observador é o princípio da seletividade. Ninguém observa tudo, ninguém seria capaz de fazê-lo uma vez que existe tanta coisa a ser observada, às vezes, num só momento. Ser bom observador significa, antes de tudo, observar o que é mais digno de atenção, julgamento que varia de indivíduo para indivíduo e de ocasião para ocasião. Desde que a observação requer atenção e que atenção depende de interesse, é claro que o bom observador precisa estar interessado no que é digno de nota. É aconselhável, portanto, criar interesse pelo que é mais digno de nota e dedicar alguma consideração a este ponto. (WOODWORTH, MARQUIS, 1971, p. 477)
\end{abstract}

Nessa mesma direção argumentativa, Gómez et al. (1999) salientam que a escolha do foco da observação baseia-se na existência de um problema ou de uma pergunta formulada pela pessoa que observa, ou seja, trata-se de uma ação deliberada de 
produção de dados, decorrente da seleção de um objeto a ser observado, o que implica juízo e tomada de decisão.

A observação, como outros procedimentos de recolha de dados, constitui um processo deliberado e sistemático que há de estar orientado por uma pergunta, propósito ou problema. Esse problema é o que dá sentido à observação em si e é o que determina aspectos tais como: o que observar; quem é observado, como se observa, quando se observa, onde se observa, quando se registram as observações, que observações se registram; como se analisam os dados procedentes da observação ou que utilidade se dá aos dados. (GÓMEZ, et al., 1999, p. 150)

Os autores sugerem uma distinção no nível de formalização das práticas de observação. Nos termos anunciados por eles, é possível distinguir pelo nível de formalização as práticas de observação, desde as menos formais, que são as observações tácitas do cotidiano, passando por um nível de observações de caráter deliberado e sistemático de situações específicas do cotidiano até as mais formais, que são as observações de caráter deliberado e sistemático guiadas por uma questão (GÓMEZ, 1999).

Dessas considerações, depreende-se que no cotidiano das instituições de educação infantil não é possível pensar em observações totalmente informais, mas, pela natureza do ato educativo, que deve se revestir de um propósito, a observação deve ter um caráter deliberado e sistemático.

Recorrendo às referências de Lankshear e Knobel (2008), relativas aos instrumentos e técnicas de coleta de dados na pesquisa educacional, destaca-se dentre os tipos de observação, a "observação com participação plena”, que mais se aproxima do que se espera como prática de observação em contextos educacionais. Conforme definição proposta,

[...] na observação com participação plena, os pesquisadores envolvemse direta e completamente com o contexto que estiver sendo investigado. [...] a participação plena requer que os pesquisadores tornem-se tanto quanto possível "participantes' da "cena" que observam. Os observadores com participação plena entendem completamente e são capazes de participar de uma prática como se 
estivessem realizando há um longo tempo. (LANKSHEAR, KNOBEL, 2008, p. 191-192)

São os próprios autores que fazem a transposição para o campo da prática educativa, ao se referirem aos professores-pesquisadores. Eles destacam como vantagem o fato de serem "participantes plenos da vida e das práticas cotidianas das próprias classes" o que "dá um peso a suas interpretações dos dados" (LANKSHEAR; KNOBEL, 2008, p. 192). Contudo, advertem sobre o perigo de terem o olhar de observadores 'contaminado' justamente pela condição de participantes. Como forma de minimizar os riscos dessa 'contaminação', indicam a necessidade de apelar a diferentes fontes de dados e, especialmente importante, partilhar com outros professores e pesquisadores as observações e os registros realizados.

Daí a importância de destacar que a observação no campo da documentação pedagógica não pode ser aquela observação a fim de verificar ideias a priori. Ao contrário, a observação deve ser uma técnica para estranhar aquilo que é familiar (FOCHI, 2015).

Esses argumentos confluem com a visão defendida por Gandini e Edwards (2002), ao se referirem aos observadores, implicados no processo investigativo próprio da documentação pedagógica, como

[...] "observadores participantes", que estão interessados em registrar cuidadosamente as várias partes das informações. Eles pretendem construir um entendimento que possa ser compartilhado acerca das maneiras como as crianças interagem com o ambiente, como elas se relacionam com os adultos e com outras crianças e como constroem o próprio conhecimento." (GANDINI; EDWARDS, 2002, p. 151)

Portanto, uma documentação pedagógica depende de uma alta qualidade de registros de observação e de grande competência na coleta, na produção e na organização dos dados. Não é possível naturalizar essa complexa tarefa, imaginando que professores e gestores da educação infantil, como numa mágica, passem a constituir fartas documentações pedagógicas, sem cumprir etapas de todo o ciclo investigativo. Trata-se, antes de tudo, de um árduo exercício, que não se cumpre isoladamente, mas 
sim, no coletivo, mediante reflexão individual e partilhada, de maneira colaborativa, no genuíno sentido de comunicação das jornadas de aprendizagens das crianças e de aprendizagens dos adultos.

\section{Considerações finais: a documentação pedagógica como possibilidade de (re)criar significados}

A documentação pedagógica representa um processo próprio de pedagogias participativas que se assentam na competência autoral e comunicativa de adultos e de crianças sensíveis na constituição de práticas educativas significativas, propiciadoras de aprendizagens experienciais crescentemente ampliadas.

Nos termos da Pedagogia-em-Participação, a perspectiva pedagógica participativa da Associação Criança, Braga, Portugal, “a documentação pedagógica é o processo para registrar a aprendizagem - a aprendizagem das crianças, mas também a aprendizagem dos profissionais e a dos pais" (OLIVEIRA-FORMOSINHO; FORMOSINHO, 2011, p. 35). Por isso mesmo, dentro dessa abordagem, a documentação pedagógica é colocada no centro do processo de aprendizagem e é concebida como sustentação da gramática curricular a que se faz defesa.

Seguindo esse mesmo sentido, nos filiamos à ideia defendida por Hoyuelos (2007) e Davoli (2011) de que a documentação pedagógica é uma estratégia tanto para argumentar como para narrar os processos de construção do conhecimento praxiológico. Na educação infantil precisamos (re)criar os significados da prática pedagógica, do papel do adulto e até mesmo da função da escola.

Quando documentamos e compartilhamos o que foi observado, registrado e interpretado à luz de um determinado quadro conceitual, comunicamos uma dada ideia de criança, de professor e de escola. (OLIVEIRA-FORMOSINHO; FORMOSINHO, 2011; FOCHI, 2015). Nesse sentido, a estratégia da documentação pedagógica se converte em uma ferramenta poderosa na reconstrução de significados.

A documentação pedagógica é, conforme sustenta Dolci (2011), uma forma de consolidar um processo pedagógico. Seguindo essa mesma ideia, "não são apenas 
memórias de algo que já aconteceu, são também processos que nos permitem compreender como fizemos o que fizemos" (DAVOLI, 2011, p. 28).

\section{Referências}

BRASIL. Ministério da Educação. Documento técnico contendo estudo sobre as experiências exitosas que já utilizam a documentação pedagógica na Educação Infantil nos segmentos creches e pré-escola. Consultor de Paulo Sergio Fochi. 54f. Brasília: Ministério da Educação, 2017.

DAHLBERG, Gunilla; MOSS, Peter; PENCE, Alan. Qualidade na educação da primeira infância: perspectivas pós-modernas. Porto Alegre/RS. Artmed. 2003.

DAVOLI, Mara. Documentar procesos, recoger siñales. In: RED TERRITORIAL DE EDUCACIÓN INFANTIL DE CATALUÑA. Documentar la vida de niños y niñas en la escuela. Barcelona: Octaedro, 2011.

DOLCI, Mariano. Afinando la vista para captar los momentos. In: RED TERRITORIAL DE EDUCACIÓN INFANTIL DE CATALUÑA. Documentar la vida de niños y niñas en la escuela. Barcelona: Octaedro, 2011.

FOCHI, Paulo. Afinal, o que os bebês fazem no berçário? comunicação, autonomia e saber-fazer de bebês em um contexto de vida coletiva. Porto Alegre: Penso, 2015.

FOCHI, Paulo Sergio. Abordagem da documentação pedagógica na investigação praxiológica de contextos de educação infantil. 2016. 217 f. Relatório de qualificação de tese (Doutorado em Educação) - Universidade de São Paulo, Programa de Pós-Graduação em Educação, São Paulo, 2016.

GANDINI, Lella.; GOLDHABER, Joane, Duas Reflexões sobre a documentação. In: GANDINI, Lella; EDWARDS, Carolyn et al (Orgs). Bambini: a abordagem italiana à educação infantil. Porto Alegre/RS. Artmed. 2002. p. 150-169.

GÓMEZ, Gregorio Rodrigues; FLORES, Javier Gil; JIMÉNEZ, Eduardo Garcia; Metodología de la investigación cualitativa. $2^{a}$. ed. Málaga. Ediciones Aljibe, 1999.

HOYUELOS, Alfredo. La ética en el pensamiento y obra pedagógica de Loris Malaguzzi. Barcelona: Octaedro, 2006.

HOYUELOS, Alfredo. Documentación como argumentación y narración. Revista Aula de Infantil, n. 39, Barcelona, 2007.

LANKSHEAR, Colin; KNOBEL, Michele. Pesquisa pedagógica: do projeto à implementação. Porto Alegre/RS. Artmed. 2008.

MALAGUZZI, Loris. Escuelas infantiles de Reggio Emilia: la inteligencia se construye usándola. Madrid: Ediciones Morata, 1995.

MALAGUZZI, Loris. La educación infantil en Reggio Emilia. Barcelona: Octaedro, 2001. 
MOSS, Peter. Prefácio. In: PAIGE-SMITH, Alice; CRAFT, Anna. (Orgs.). O desenvolvimento da prática reflexiva na educação infantil. Porto Alegre: Artmed, 2010.

OLIVEIRA-FORMOSINHO, Julia. Pedagogia(s) da infância: reconstruindo uma práxis de participação. In: OLIVEIRA-FORMOSINHO, Julia et al. (Orgs.) Pedagogia(s) da infância: dialogando com o passado, construindo o futuro. Porto Alegre: Artmed, 2007. p. 13-36.

OLIVEIRA-FORMOSINHO, João; FORMOSINHO, Julia. A Perspectiva Pedagógica da Associação Criança: A Pedagogia-em-Participação, IN: OLIVEIRA-FORMOSINHO, João; FORMOSINHO,Julia (Orgs). O Trabalho de Projeto na Pedagogia-em-Participação. Porto/Pt. Porto Editora, 2011. p. 11-45.

PAIGE-SMITH, Alice; CRAFT, Anna. O que é refletir sobre a prática? In. PAIGE-SMITH, A.; CRAFT, A. (Orgs.). $O$ desenvolvimento da prática reflexiva na educação infantil. Porto Alegre: Artmed, 2010.

PINAZZA, Mônica Apezzatto. A. Formação de profissionais da educação infantil em contextos integrados: informes de uma investigação-ação. 2014. Tese (Livre docência), Universidade de São Paulo, São Paulo, 2014.

RINALDI, Carla. Diálogos com Reggio Emilia: escutar, investigar e aprender. São Paulo: Paz e Terra, 2012.

WOODWORTH, Robert S.; MARQUIS, Donald G. Psicologia. São Paulo, Companhia Editora Nacional. 1971 (Atualidades Pedagógicas, 67). 